\title{
Using airborne HIAPER Pole-to-Pole Observations (HIPPO) to evaluate model and remote sensing estimates of atmospheric carbon dioxide
}

\author{
Christian Frankenberg ${ }^{1,2}$, Susan S. Kulawik ${ }^{3}$, Steven C. Wofsy ${ }^{4}$, Frédéric Chevallier ${ }^{5}$ Bruce Daube $^{4}$, Eric A. Kort ${ }^{6}$, \\ Christopher O'Dell ${ }^{7}$, Edward T. Olsen ${ }^{2}$, and Gregory Osterman ${ }^{2}$ \\ ${ }^{1}$ Division of Geology and Planetary Sciences, California Institute of Technology, Pasadena, CA, USA \\ ${ }^{2}$ Jet Propulsion Laboratory, California Institute of Technology, Pasadena, CA, USA \\ ${ }^{3}$ Bay Area Environmental Research Institute, Sonoma, CA 95476, USA \\ ${ }^{4}$ Harvard University, Cambridge, MA, USA \\ ${ }^{5}$ Laboratoire des Sciences du Climat et de l'Environnement (LSCE), Gif sur Yvette, France \\ ${ }^{6}$ Climate and Space Sciences and Engineering, University of Michigan, Ann Arbor, MI, USA \\ ${ }^{7}$ Cooperative Institute for Research in the Atmosphere (CIRA), Fort Collins, CO, USA
}

Correspondence to: Christian Frankenberg (cfranken@ caltech.edu)

Received: 25 November 2015 - Published in Atmos. Chem. Phys. Discuss.: 19 January 2016

Revised: 10 May 2016 - Accepted: 26 May 2016 - Published: 27 June 2016

\begin{abstract}
In recent years, space-borne observations of atmospheric carbon dioxide $\left(\mathrm{CO}_{2}\right)$ have been increasingly used in global carbon-cycle studies. In order to obtain added value from space-borne measurements, they have to suffice stringent accuracy and precision requirements, with the latter being less crucial as it can be reduced by just enhanced sample size. Validation of $\mathrm{CO}_{2}$ column-averaged dry air mole fractions $\left(\mathrm{XCO}_{2}\right)$ heavily relies on measurements of the Total Carbon Column Observing Network (TC$\mathrm{CON}$ ). Owing to the sparseness of the network and the requirements imposed on space-based measurements, independent additional validation is highly valuable. Here, we use observations from the High-Performance Instrumented Airborne Platform for Environmental Research (HIAPER) Pole-to-Pole Observations (HIPPO) flights from 01/2009 through 09/2011 to validate $\mathrm{CO}_{2}$ measurements from satellites (Greenhouse Gases Observing Satellite - GOSAT, Thermal Emission Sounder - TES, Atmospheric Infrared Sounder - AIRS) and atmospheric inversion models (CarbonTracker CT2013B, Monitoring Atmospheric Composition and Climate (MACC) v13r1). We find that the atmospheric models capture the $\mathrm{XCO}_{2}$ variability observed in HIPPO flights very well, with correlation coefficients $\left(r^{2}\right)$ of 0.93 and 0.95 for CT2013B and MACC, respectively. Some larger discrepan-
\end{abstract}

cies can be observed in profile comparisons at higher latitudes, in particular at $300 \mathrm{hPa}$ during the peaks of either carbon uptake or release. These deviations can be up to $4 \mathrm{ppm}$ and hint at misrepresentation of vertical transport.

Comparisons with the GOSAT satellite are of comparable quality, with an $r^{2}$ of 0.85 , a mean bias $\mu$ of $-0.06 \mathrm{ppm}$, and a standard deviation $\sigma$ of $0.45 \mathrm{ppm}$. TES exhibits an $r^{2}$ of $0.75, \mu$ of $0.34 \mathrm{ppm}$, and $\sigma$ of $1.13 \mathrm{ppm}$. For AIRS, we find an $r^{2}$ of $0.37, \mu$ of $1.11 \mathrm{ppm}$, and $\sigma$ of $1.46 \mathrm{ppm}$, with latitude-dependent biases. For these comparisons at least 6 , 20 , and 50 atmospheric soundings have been averaged for GOSAT, TES, and AIRS, respectively. Overall, we find that GOSAT soundings over the remote Pacific Ocean mostly meet the stringent accuracy requirements of about $0.5 \mathrm{ppm}$ for space-based $\mathrm{CO}_{2}$ observations.

\section{Introduction}

Space-borne measurements of atmospheric carbon dioxide $\left(\mathrm{CO}_{2}\right)$ can provide unique constraints on carbon exchanges between land, ocean, and atmosphere on a global scale. Results from the SCanning Imaging Absorption spectroMeter for Atmospheric CHartograpHY (SCIAMACHY) (e.g., 


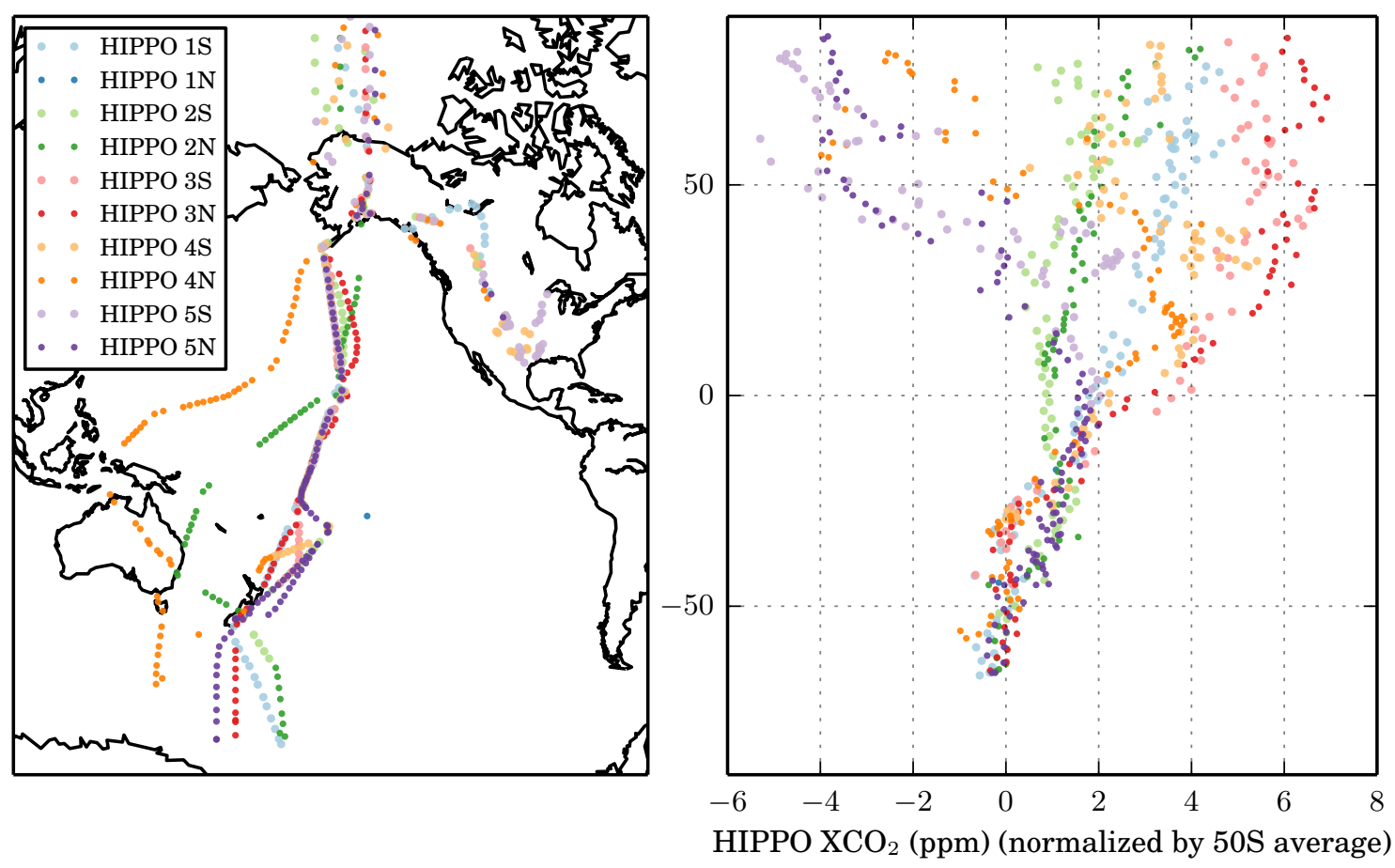

Figure 1. Left: Overview of the 5 HIPPO campaigns, taken place in January 2009 (1), November 2009 (2), March/April 2010 (3), June/July 2011 (4) and August/September 2011 (5). Campaigns are separated by Southbound (S) and Northbound (N) and each dot indicates a separate HIPPO vertical profile. Right: Latitudinal gradients of column-averaged $\mathrm{CO}_{2}$ mixing ratios with the campaign average at 50S subtracted. Above the highest HIPPO flight altitude, profiles have been extended with CarbonTracker CT2013B in order to compute the column average.

Schneising et al., 2014) and the Greenhouse Gases Observing Satellite (GOSAT) (Lindqvist et al., 2015) have shown that they can reproduce the seasonal cycle as well as the secular trend of total column $\mathrm{CO}_{2}$ abundances reasonably well (Kulawik et al., 2015). However, accuracy requirements are very stringent (Miller et al., 2007), warranting large-scale biases of less than $0.5-1 \mathrm{ppm}$, being less than $0.3 \%$ of the global background concentration. This is one of the most challenging remote sensing measurements from space as we want to reproduce not only known average seasonal cycles and trends but also small inter-annual deviations, resolved to subcontinental scales. There have been successes in doing so (e.g., Basu et al., 2014; Guerlet et al., 2013) but controversies regarding overall retrieval accuracy on the global scale still remain (Chevallier, 2015) and can neither be fully refuted nor confirmed with validations against the Total Column Carbon Observing Network (TCCON) (e.g., Kulawik et al., 2015). In addition, total uncertainties might be a mix of measurement and modeling biases (Houweling et al., 2015), for which uncertainties in vertical transport can play a crucial role (Stephens et al., 2007; Deng et al., 2015).

In this manuscript, we use the term accuracy to refer to systematic errors that remain after infinite averaging and can vary in space and time. Globally constant systematic errors are easy to correct but those with spatio-temporal dependencies can have a potentially large impact on flux inversions.

Given the importance of the underlying scientific questions regarding the global carbon cycle and the challenging aspect of both the remote sensing aspect as well as the atmospheric inversion, every additional independent validation beyond ground-based data can be crucial. Here, we use measurements from the High-Performance Instrumented Airborne Platform for Environmental Research (HIAPER) Pole-to-Pole Observations (HIPPO) program (Wofsy, 2011) to evaluate both atmospheric models as well as remotely sensed estimates of atmospheric $\mathrm{CO}_{2}$.

\section{Data description}

\subsection{HIPPO}

The HIPPO project, a sequence of five global aircraft measurement programs, sampled the atmosphere from (almost) the North Pole to the coastal waters of Antarctica, from the surface to $14 \mathrm{~km}$ a.g.l., spanning the seasons (Wofsy, 2011). This enables a comparison of individual sub-columns of air but also of $\mathrm{CO}_{2}$ column-averaged dry air mole fractions, denoted $\mathrm{XCO}_{2}$, if the profile can be reliably extended above $14 \mathrm{~km}$ a.g.l. As the troposphere dominates the variabil- 
ity in $\mathrm{XCO}_{2}$, errors induced by extending profiles are supposed to be small. The campaigns covered different years as well as different seasons, namely HIPPO 1: 8-30 January 2009, HIPPO 2: 31 October-22 November 2009, HIPPO 3: 24 March-16 April 2010, HIPPO 4: 14 June-11 July 2011, and HIPPO 5: 9 August-9 September 2011.

Figure 1 shows an overview of the locations of the HIPPO profiles taken during different campaigns. As the five campaigns covered the years 2009 through 2011, we normalized the latitudinal cross section plot by subtracting the average $\mathrm{XCO}_{2}$ around $50^{\circ} \mathrm{S}$. In the Southern Hemisphere, the shape of the latitudinal gradients only changes marginally between seasons while the amplitude at the higher latitudes in the Northern Hemisphere spans about 10 ppm, with the strongest drawdown during August/September for HIPPO 5 and the highest concentrations during HIPPO 3 in March/April. The data set thus covers a wide range of atmospheric $\mathrm{CO}_{2}$ profiles especially in the Northern Hemisphere where the strong biogenic cycle causes strong seasonality in $\mathrm{CO}_{2}$ fluxes.

\subsection{Atmospheric models}

For the comparison of HIPPO against model data as well as for a more robust comparison of HIPPO against total column satellite $\mathrm{CO}_{2}$ observations, we use two independent atmospheric models that provide four-dimensional (4-D) $\mathrm{CO}_{2}$ fields (space and time) that are consistent with in situ measurements of atmospheric $\mathrm{CO}_{2}$. The two main differences between these models are the use of a different inversion scheme and underlying transport model. In addition, both models were used to extend individual HIPPO profiles from the highest flight altitude to the top of atmosphere when compared to total column estimates from the satellite.

\subsubsection{CarbonTracker CT2013B}

CarbonTracker (Peters et al., 2007 with updates documented at http://carbontracker.noaa.gov) is a $\mathrm{CO}_{2}$ modeling system developed by the NOAA Earth System Research Laboratory. CarbonTracker (CT) estimates surface emissions of carbon dioxide by assimilating in situ data from NOAA observational programs, monitoring stations operated by Environment Canada, and numerous other international partners using an ensemble Kalman filter optimization scheme built around the TM5 atmospheric transport model (Krol et al., 2005; http://www.phys.uu.nl/ tm5/). Here we use the latest release of CarbonTracker, CT2013B, which provides $\mathrm{CO}_{2}$ mole fraction fields globally from 2000 to 2012. In this study, we interpolate modeled $\mathrm{CO}_{2}$ mole fractions to the times and locations of individual HIPPO observations.

\subsubsection{MACC v13r1}

Monitoring Atmospheric Composition and Climate (MACC; http://www.copernicus-atmosphere.eu/) is the European Union-funded project responsible for the development of the pre-operational Copernicus atmosphere monitoring service. Its $\mathrm{CO}_{2}$ atmospheric inversion product relies on a variational Bayesian formulation, developed by LSCE (Laboratoire des Sciences du Climat et de l'Environnement), which estimates 8-day grid-point daytime/nighttime $\mathrm{CO}_{2}$ fluxes and the grid point total columns of $\mathrm{CO}_{2}$ at the initial time step of the inversion window. It uses the global tracer transport model LMDZ (Laboratoire de Météorologie Dynamique Zoom, Hourdin et al., 2006), driven by the wind analyses from the ECMWF (European Centre for Medium-Range Weather Forecasts). Version $13 \mathrm{r} 1$ of the MACC product covers the period from 1979 to 2013, at horizontal resolution $3.75^{\circ} \times 1.9^{\circ}$ (longitude-latitude). It assimilated the dry air mole fraction measurements from $131 \mathrm{CO}_{2}$ stations over the globe in a unique 35-year assimilation window (see the list of sites in Tables S1 and S2 of Chevallier, 2015). For this study, the model simulation has been interpolated to the time and location of the individual observations using the subgrid parametrization of the LMDZ advection scheme in the three dimensions of space (Hourdin and Armengaud, 1999). For the sake of brevity, we refer to MACC version 13r1 simply as MACC.

\subsection{Satellite data}

We use remotely sensed $\mathrm{CO}_{2}$ observations from three different instruments, namely GOSAT, the Thermal Emission Sounder (TES), and the Atmospheric Infrared Sounder (AIRS). As most HIPPO profiles took place over the oceans, SCIAMACHY was not included in the analysis because it lacks a dedicated Glint Mode measurement. While GOSAT $\mathrm{CO}_{2}$ is representative of the column-averaged dry air mole fraction $\left(\mathrm{XCO}_{2}\right)$, both TES and AIRS are most sensitive to the atmosphere around 500 and $300 \mathrm{hPa}$, respectively.

\subsubsection{GOSAT (ACOS B3.5)}

GOSAT takes measurements of reflected sunlight in three shortwave infrared bands with circular footprints (diameter of $10.5 \mathrm{~km}$ ) at nadir (Hamazaki et al., 2005; Kuze et al., 2009). Science data started in July 2009. In this work, we use $\mathrm{XCO}_{2}$ retrievals produced by NASA's Atmospheric $\mathrm{CO}_{2}$ Observations from Space (ACOS) project, version 3.5 (see O'Dell et al., 2012 for retrieval details), which is very similar to the B3.4 version described in https://co2.jpl.nasa.gov/static/docs/v3.4_ DataUsersGuide-RevB_131028.pdf. The data and bias correction as used here is identical to the data set investigated in Kulawik et al. (2015).

\subsubsection{TES}

TES is on the Earth Observing System Aura (EOS-Aura) satellite and makes high spectral resolution nadir measurements in the thermal infrared $\left(660-2260 \mathrm{~cm}^{-1}\right.$, with unapodized resolution of $0.06 \mathrm{~cm}^{-1}$ and apodized resolution 
of $0.1 \mathrm{~cm}^{-1}$ ). TES was launched in July 2004 in a sunsynchronous orbit at an altitude of $705 \mathrm{~km}$ with an equatorial crossing time of 13:38 (local mean solar time) and with a repeat cycle of 16 days. From September 2004 to June 2011, TES collected global survey observations, averaging $\approx 500$ good quality $\mathrm{CO}_{2}$ day/night and land/ocean observations with a cloud optical depth less than 0.5 between $40^{\circ} \mathrm{S}$ and $45^{\circ} \mathrm{N}$. The peak sensitivity of $\mathrm{CO}_{2}$ is about $500 \mathrm{hPa}$, with full-width half-maximum sensitivity between 200 and $800 \mathrm{hPa}$. TES $\mathrm{CO}_{2}$ requires averaging to reduce random errors, which can approach $\approx 6 \mathrm{ppm}$ for a single observation to $\approx 1.3 \mathrm{ppm}$ for monthly regional scales. For more details on TES CO 2 , see Kulawik et al. (2013).

\subsubsection{AIRS (v5)}

The AIRS version 5 tropospheric $\mathrm{CO}_{2}$ product is a retrieval of the weighted partial-column dry volume mixing ratio characterizing the mid- to upper-tropospheric $\mathrm{CO}_{2}$ concentration. The product is derived by the technique of vanishing partial derivatives (VPD) described in Chahine et al. (2005) and is reported at a nominal nadir resolution of $90 \mathrm{~km} \times 90 \mathrm{~km}$ over the globe over the latitude range of $60^{\circ} \mathrm{S}$ to $90^{\circ} \mathrm{N}$ and time span of September 2002 to present.

The VPD method assumes a $\mathrm{CO}_{2}$ profile that is a linearly time-dependent global average constant volume mixing ratio throughout the atmosphere. Using that prior profile, the VPD derives $\mathrm{CO}_{2}$ by shifting the $\mathrm{CO}_{2}, \mathrm{~T}$, q, and $\mathrm{O}_{3}$ profiles and minimizing the residuals between the cloud-cleared radiances and those resulting from the forward calculation for channel subsets selected to avoid contamination by surface emission (except in regions of high topography). Further, it localizes the maximum sensitivity to variations of $\mathrm{CO}_{2}$ concentration to the pressure regime spanning from 300 to $700 \mathrm{hPa}$.

In normal practice, the AIRS level 2 products ingested by the $\mathrm{CO}_{2}$ post-processing retrieval stage are retrieved using the combination of the infrared instrument and a companion Advanced Microwave Sounding Unit (AMSU). The 57-year expected lifetime of AMSU based on NOAA experience is much shorter than that of the AIRS instrument, so an alternate level 2 retrieval using only the infrared radiances (AIRS_Only) was developed. The VPD retrieval normally ingests the combined Infrared/Mid Wave (IR/MW) retrieval system products. Beginning in January 2011 the degradation of the AMSU channel 5 noise figure significantly reduced the IR/MW L2 product yield so that the ingest was shifted to the IR-only L2 product.

Olsen and Licata (2014) compare the IR/MW-based and IR-only-based $\mathrm{CO}_{2}$ retrievals over the globe for 2010-2011 and for collocations with the deep-dip HIPPO 2, HIPPO 3, HIPPO 4 and HIPPO 5 profiles. Their global analysis reveals that the zonal monthly average difference rarely exceeds $0.5 \mathrm{ppm}$ except at the high northern latitudes in January and October, where fluctuations resulting from small number statistics dominate. Their analysis against HIPPO employs only the deep-dip measured profiles, i.e., those in which the aircraft reached the $190 \mathrm{hPa}$ pressure level. This ensures good in situ measurement coverage of the AIRS sensitivity profile and minimizes the error introduced by their simple approximation of extending the aircraft profile into the stratosphere by replicating the highest altitude measurement. During the HIPPO 2 and HIPPO 3 campaigns the AMSU channel 5 noise figure was acceptable, whereas during the HIPPO 4 and HIPPO 5 campaigns it progressively degraded at a rapid rate. For all campaigns, the two sets of collocations, averaging AIRS retrievals within $\pm 24 \mathrm{~h}$ and $500 \mathrm{~km}$ of the aircraft profile, exhibit the same bias and root mean square (rms) to within $1 \mathrm{ppm}$ for $|l a t| \leq 60^{\circ}$. The current study extends the in situ measurements to higher altitude by the means of CarbonTracker and MACC model output thereby allowing for the use of all HIPPO profiles rather than only the deep-dip profiles. Our results are statistically consistent with the latitudedependent biases reported by Olsen and Licata (2014) and give a more detailed view of the scatter as a function of latitude.

\section{HIPPO - model inter-comparisons}

Figure 2 shows an overview of model-HIPPO differences at three pressure levels as well as $\mathrm{XCO}_{2}$, the total column average. For the differences in $\mathrm{XCO}_{2}$, the respective model has been used to extend the HIPPO profiles from its highest altitude to the top of atmosphere; hence, part of the smaller differences observed in $\mathrm{XCO}_{2}$ comparisons can stem from the fact that the model contributes slightly to the HIPPO-based $\mathrm{XCO}_{2}$ as well, though the tropospheric variability should dominate. As can be seen in the left panels, not all HIPPO profiles extend up to $300 \mathrm{hPa}$.

Unsurprisingly, model-data mismatches at individual levels are substantially higher than in the total column, about a factor of 2. Many differences are not consistent between the two models, for example during HIPPO 4N, extending from West Papua northwards. In MACC, there is first a substantial underestimation throughout the profile and then an overestimation further north. In CT2013B, no obvious discrepancies can be observed. In other areas, such as the same HIPPO $4 \mathrm{~N}$ path south of Alaska, MACC appears rather consistent but CT2013B is much higher at $800 \mathrm{hPa}$ but much lower at $500 \mathrm{hPa}$, with a slight underestimation in the total column.

Figure 3 provides an in-depth review of HIPPO - model comparisons for profiles averaged by latitudinal bands and campaign. In most cases, profiles agree to within $1 \mathrm{ppm}$ with a few notable exceptions, mostly at higher latitudes during the drawdown or respiration maximum in HIPPO 5 and 3, respectively. These are typically associated with steep vertical gradients around $300 \mathrm{hPa}$, both in HIPPO 5 and 3, albeit with different signs. In most other cases, the differences even in the profiles are usually below $1 \mathrm{ppm}$, underlining the strin- 


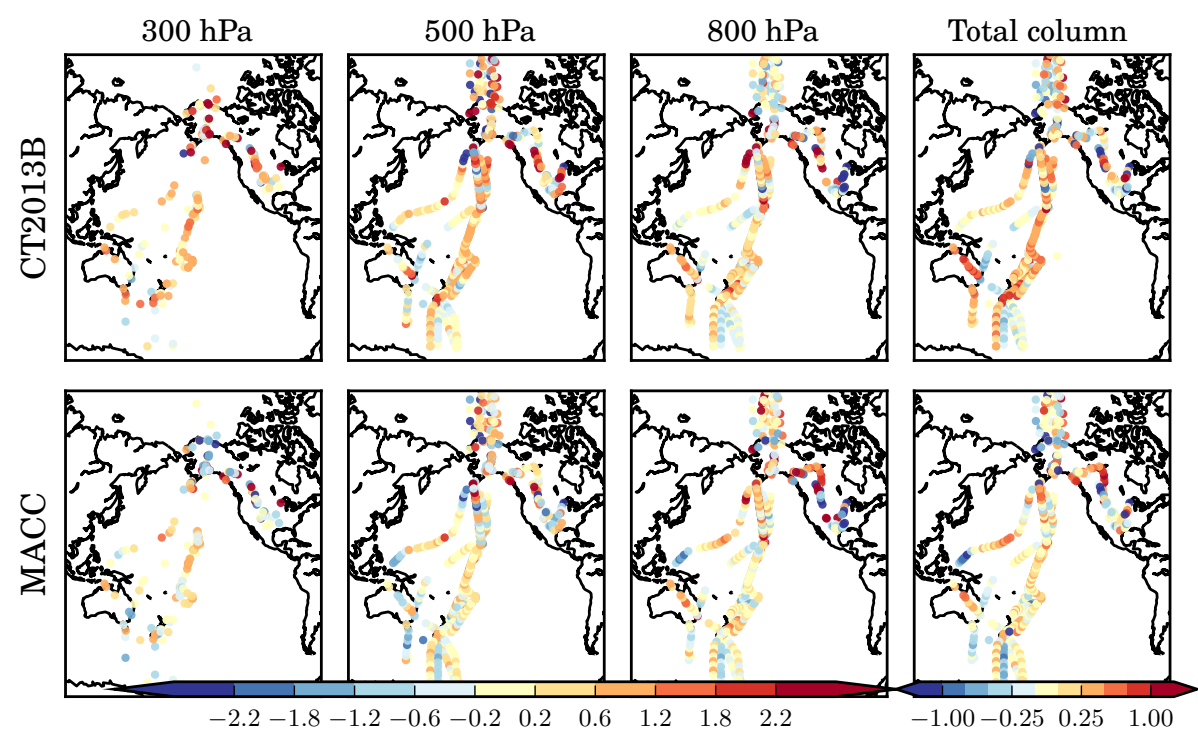

Figure 2. Top row, from left to right: CT2013B-HIPPO differences at 300, 500, $800 \mathrm{hPa}$, and column-averaged mixing ratio of $\mathrm{CO}_{2}$. Bottom row: as for the top row but for the MACC model. Note the change in color scale between layer and total column differences. All HIPPO campaigns are included.

gent accuracy requirements for space-based $\mathrm{CO}_{2}$ measurements, as atmospheric models optimized with respect to the ground-based network already model oceanic background concentrations fairly well. However, the caveat is that these ground-based stations are also located in remote regions, ideally not affected by local sources. On smaller spatial scales near sources, space-based measurements can provide valuable information even in the presence of potential large-scale biases.

Figure 4 shows an in-depth comparison of the largest model-HIPPO discrepancies, namely the high latitude profiles during HIPPO 3 and 5. As one can see in the left panels, the seasonal cycles in the mid-troposphere and at $200 \mathrm{hPa}$ can be opposite, with large $\mathrm{CO}_{2}$ values in the upper atmosphere during the largest $\mathrm{CO}_{2}$ drawdown and vice versa during the peak of respiration. Model-HIPPO mismatches are most obvious and similar between models in HIPPO 3 (March/April 2010), with differences reaching up to $4 \mathrm{ppm}$ at $300 \mathrm{hPa}$. This is consistent with a comparison against the GEOS-Chem model by Deng et al. (2015), who studied the impact of discrepancies in stratosphere-troposphere exchange on inferred sources and sinks of $\mathrm{CO}_{2}$. In HIPPO 5, at the end of the growing season, the situation is reversed as the profile slopes change sign after the large $\mathrm{CO}_{2}$ uptake during summer. For HIPPO 5, the deviations for CT2013B are somewhat smaller but it can be seen that most models suffer from these potential biases if large vertical gradients exist. Overall, both CT2013B as well as MACC show a good agreement with HIPPO over the oceans.

\section{Comparisons of column-averaged mixing ratios}

Here, we look at $\mathrm{XCO}_{2}$, derived using absorption spectroscopy of reflected sunlight recorded by near-infrared spectrometers such as SCIAMACHY, GOSAT, or Orbiting Carbon Observatory-2 (OCO-2). In this paper, we only used data from GOSAT as it is the only instrument having sampled in Glint mode during the HIPPO investigation. SCIAMACHY data have not been used as it has no dedicated glint mode and the SCIAMACHY products (e.g., Reuter et al., 2011) are limited to retrievals over land.

For the comparison of column-averaged mixing ratios, we need to extend the HIPPO profiles to the top of atmosphere. For this, we use the respective atmospheric model for comparison. In addition, we computed the average HIPPO $\mathrm{XCO}_{2}$ for each campaign using all the data and subsequently removed it from individual measurements, both from the HIPPO, model and satellite data. This ensures that observed correlations are driven predominantly by spatial gradients within a campaign period and not by the secular trend. For the HIPPO comparison against GOSAT data, we take the instrument sensitivity into account by applying the averaging kernel to the difference of the true profile (using the modelextended HIPPO data set as truth) and the respective a priori profile. We perform this correction using both model extensions independently and then use the average of the two.

\subsection{Atmospheric models}

In terms of $\mathrm{XCO}_{2}$, both atmospheric models used here compare well against HIPPO, as can be seen in Figs. 5 and 6 . Even after normalization with the campaign average, the cor- 

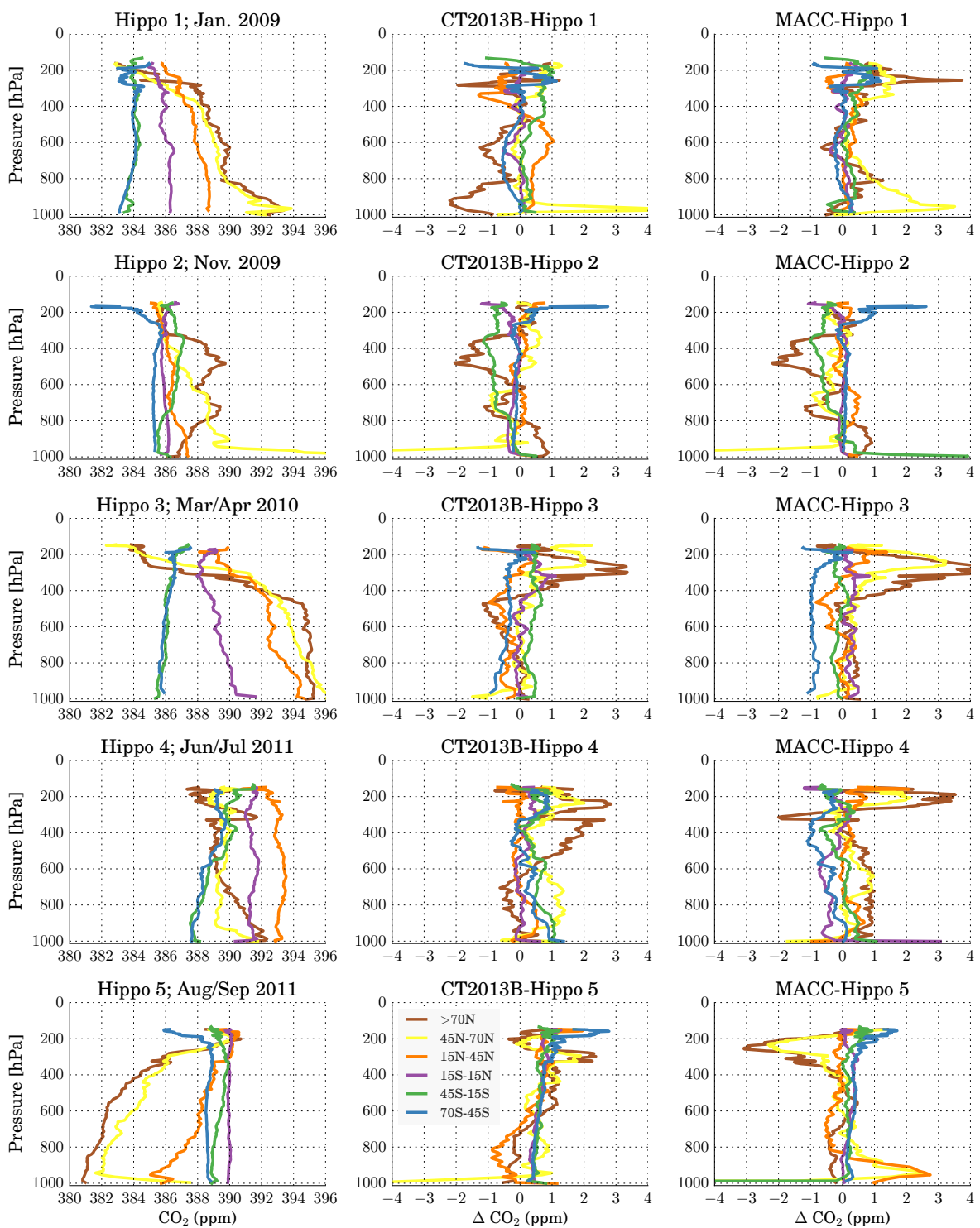

Figure 3. Summary of averaged $\mathrm{CO}_{2} \mathrm{HIPPO}$ profiles in ppm (left column) and model-HIPPO differences (middle and right column), separated by latitudinal bands (color coded) and HIPPO campaign (separate rows).

relation coefficients and slopes are $r^{2}=0.93$ (slope $=0.95$ ) for CT2013B and $r^{2}=0.95$ (slope $=1.00$ ) for MACC. South of $20^{\circ} \mathrm{N}$, almost all data points lie within $\pm 1 \mathrm{ppm}$ with some outliers of up to $3 \mathrm{ppm}$ at higher latitudes, mostly over the continents (see Fig. 2).

These numbers should not be used to compare the models against each other because, as evident in Fig. 2, there are regions where either one or the other model is in better agreement with HIPPO. In conclusion, one can state that most model mismatches are below $1 \mathrm{ppm}$ in remote areas, such as the oceans, and can reach $2-3$ ppm over the continents with potentially higher values in under-sampled areas with high $\mathrm{CO}_{2}$ uptake such as the US corn belt. In addition, it should be mentioned that both models ingest a multitude of $\mathrm{CO}_{2}$ measurements at US ground-based stations and areas further away might be less well modeled. However, the excellent agreement provides a benchmark against which satellite retrievals have to be measured.

\subsection{GOSAT}

The comparison of GOSAT satellite data against HIPPO is somewhat more complicated because there is not necessarily a matching GOSAT measurement with each HIPPO profile. For coincidence criteria, we follow exactly Kulawik et al. (2015), based on the dynamic co-location criteria detailed in Wunch et al. (2011) and Keppel-Aleks et al. (2011, 2012). In addition, we require that the difference of CT2013B sampled at the HIPPO and the actual GOSAT location is less than 

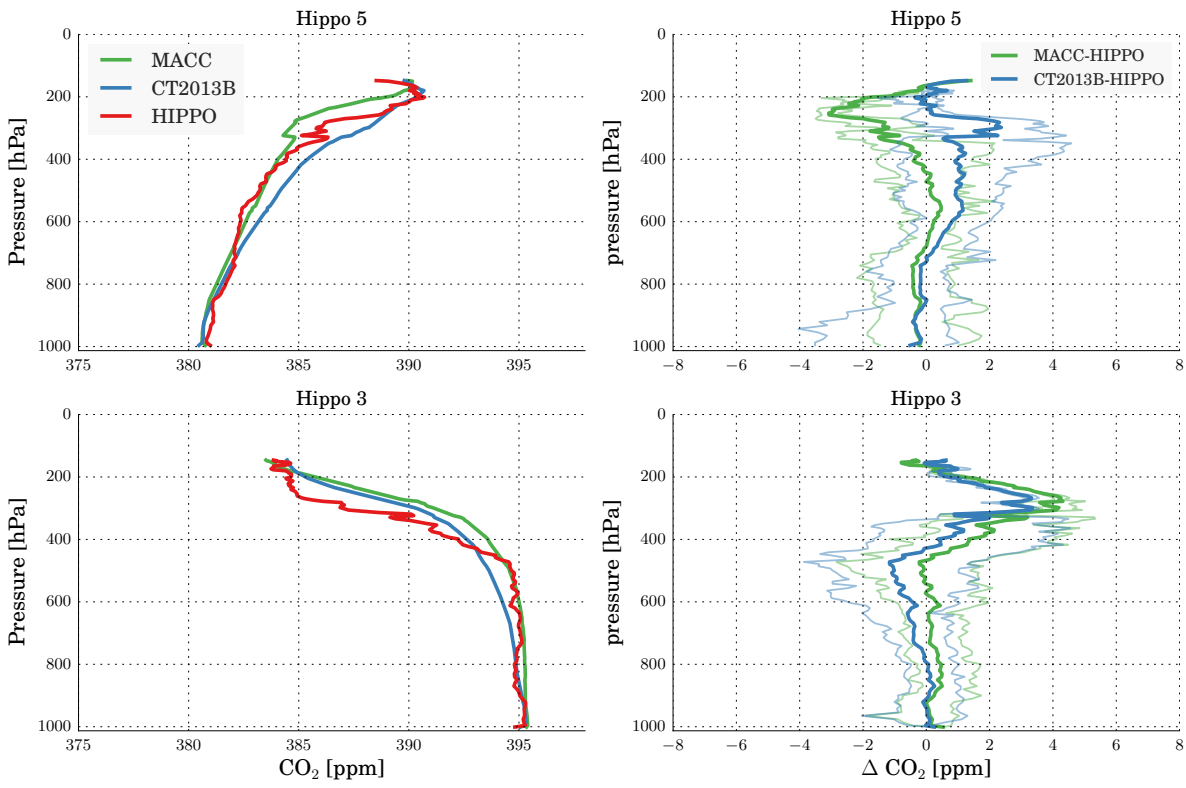

Figure 4. Averaged HIPPO and matched model profiles for latitudes $>70^{\circ} \mathrm{N}$ during HIPPO 3 and 5, respectively. The left panels show model and HIPPO profiles and the right panels show model-HIPPO average differences as well as their range in the thinner and somewhat transparent colors.
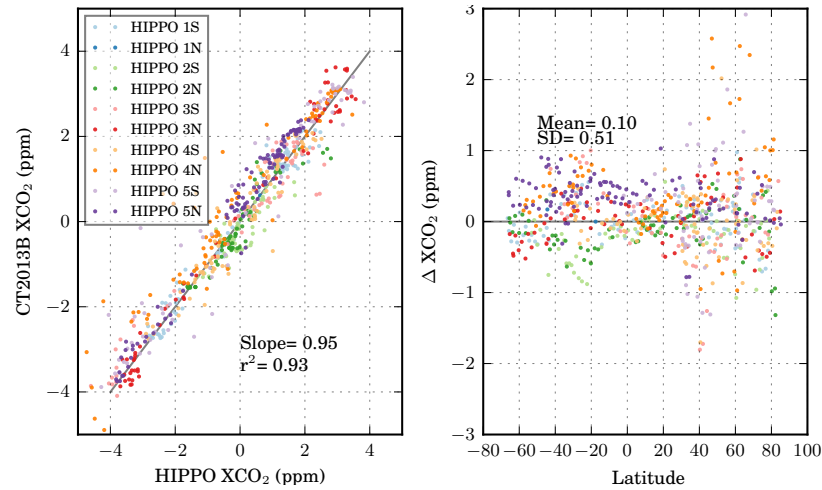

Figure 5. Left: scatter plot of normalized (with campaign average) $\mathrm{XCO}_{2}$ computed from individual HIPPO profiles ( $x$ axis) against corresponding CT2013B data. Right: difference plot of $\mathrm{XCO}_{2}$ against latitude. Campaigns as well as north and southbound tracks are color coded.

$0.5 \mathrm{ppm}$, thereby bounding the error introduced by the spatial mismatch between HIPPO and respective GOSAT soundings. For each match, the standard error in the GOSAT $\mathrm{XCO}_{2}$ average is computed using the standard deviation of all corresponding GOSAT co-locations divided by the square root of the number of co-locations.

For the GOSAT comparison, we require at least five co-located GOSAT measurement per HIPPO profile, all of which are subsequently averaged before comparison against HIPPO. HIPPO $\mathrm{XCO}_{2}$ is computed as the average of MACC
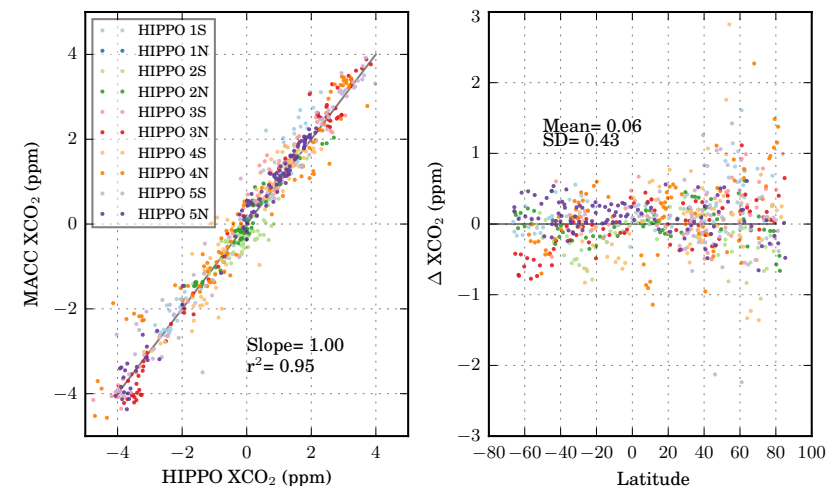

Figure 6. Left: scatter plot of normalized (with campaign average) $\mathrm{XCO}_{2}$ computed from individual HIPPO profiles ( $x$ axis) against corresponding MACC data. Right: difference plot of $\mathrm{XCO}_{2}$ against latitude. Campaigns as well as north and southbound tracks are color coded.

and CT2013B extended HIPPO profiles with the difference between the two used as uncertainty range for HIPPO.

In Fig. 7, the scatter plot of HIPPO vs. GOSAT is depicted. It is obvious that the data density is far lower than that of the models because (a) HIPPO 1 is not overlapping in time and (b) only a subset of HIPPO profiles is matched with enough co-located GOSAT soundings. This gives rise to a reduced dynamic range in $\mathrm{XCO}_{2}$, from about a -1.5 to $3 \mathrm{ppm}$ difference to the campaign average. However, both slope and $r^{2}$ are also in excellent agreement with HIPPO and only very few points are exceeding a $1 \mathrm{ppm}$ difference. Those that are 

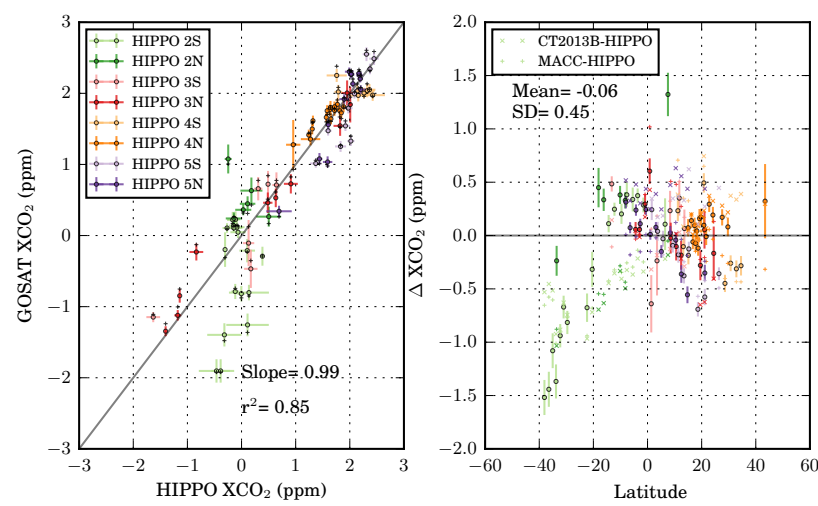

Figure 7. Left: scatter plot of normalized (with campaign average) $\mathrm{XCO}_{2}$ computed from individual HIPPO profiles ( $x$ axis) against corresponding GOSAT data. Right: difference plot of $\mathrm{XCO}_{2}$ against latitude. Campaigns as well as north and southbound tracks are color coded. For comparison, the right panel also shows the modelHIPPO differences in smaller symbols without error bar (MACC as “+”, CT2013B as “x”).

$<-1 \mathrm{ppm}$ are also associated with larger uncertainties induced by model extrapolation, as seen in the larger error bars for HIPPO in the left panel (in particular for HIPPO 2S). The right panel shows the discrepancies for the models as well, just for the subset that could be compared against GOSAT and using the model sampled at the GOSAT locations.

One can see that it is hard to make a clear statement on whether GOSAT or the models compare better with HIPPO. Figure 8 shows this comparison in more detail, plotting model-HIPPO differences on the $x$ axis and GOSAT-model differences on the $y$ axis. As before, the error bar for GOSAT is derived as the standard error in the mean and the model error bar by using the variability of HIPPO $\mathrm{XCO}_{2}$ using the two different models to extrapolate to the top-of-atmosphere (and the average of the two is defined as HIPPO $\mathrm{XCO}_{2}$. The center box spans a range from -0.5 to $0.5 \mathrm{ppm}$, a strict requirement for systematic biases (GHG-CCI, 2014). The green and red shaded areas indicated regions where either the GOSAT data meet the $0.5 \mathrm{ppm}$ requirement but the models do not (green) or vice versa (red). Given the small amount of samples, it is premature to draw strong conclusions but it appears that somewhat more points lie in the green area. It also has to be pointed out that pure measurement unsystematic noise also contributes to the scatter in GOSAT.

For MACC, there is even a noticeable correlation between MACC-HIPPO and GOSAT-HIPPO with an $r^{2}$ of 0.26 . This can hint at either small-scale features caught by HIPPO and missed by both GOSAT and models or small systematic variability between the exact HIPPO and GOSAT co-location. Most of the samples causing the high $r^{2}$ are located in the lower left quadrant, underestimated by GOSAT as well as both models and apparently all within HIPPO $2 \mathrm{~S}$, located between 40 and $20^{\circ} \mathrm{S}$.
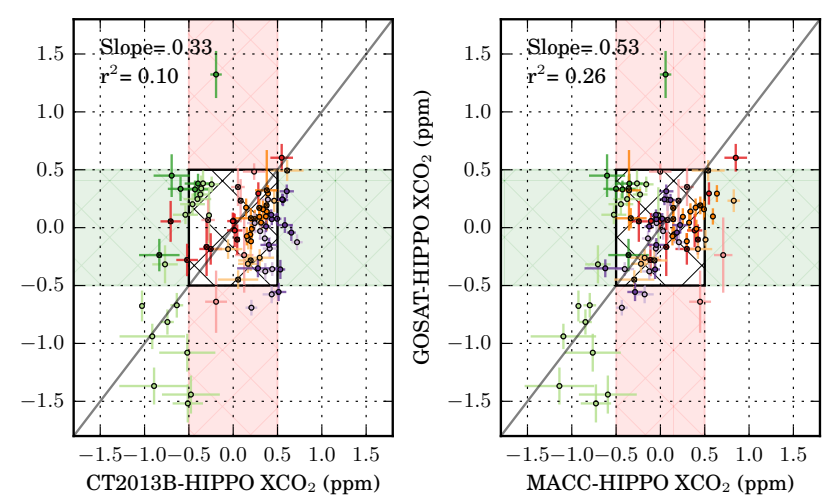

Figure 8. Left: scatter plot of $\Delta \mathrm{XCO}_{2}$ (CT-HIPPO) against $\Delta$ $\mathrm{XCO}_{2}$ (GOSAT-HIPPO), using just the GOSAT subsets. Right: same as left but using MACC instead of CT2013B. The inner box represents the area where both model and GOSAT are within $0.5 \mathrm{ppm}$ compared to HIPPO, which corresponds to the very stringent accuracy requirement. The green and red shaded areas correspond to regions where the satellite deviates less than the models and is within $0.5 \mathrm{ppm}$ (green) as well as where the models deviate less than GOSAT (red). The white cells on the outer edges indicate areas where both deviate more than $0.5 \mathrm{ppm}$ overall.

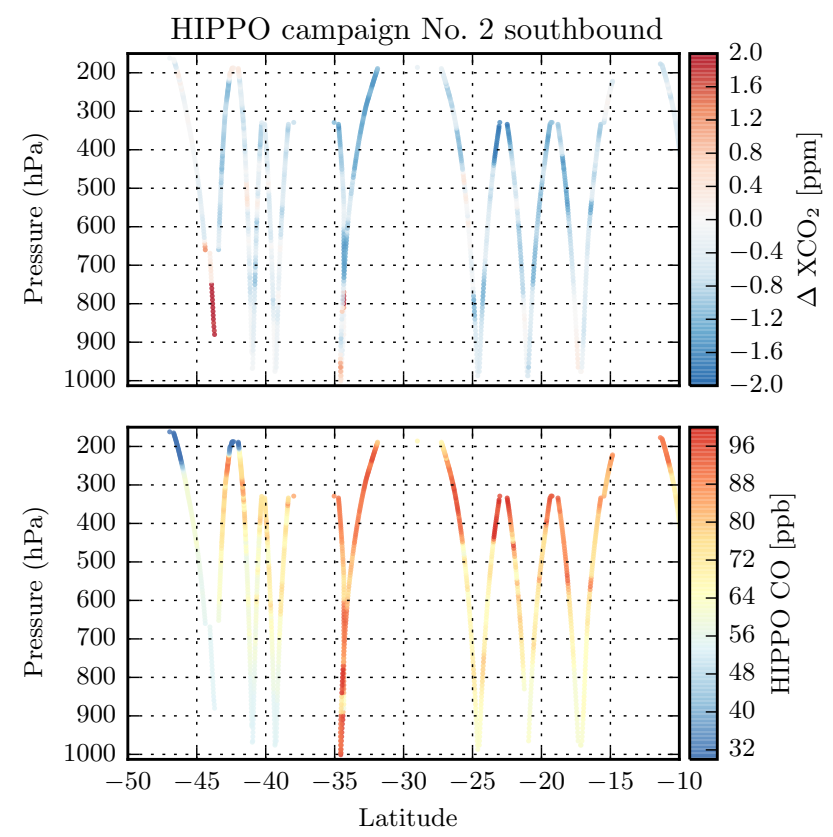

Figure 9. Top: MACC-HIPPO $\mathrm{CO}_{2}$ differences (ppm) as a function of latitude and pressure level during the HIPPO 2 southbound campaign, recorded on 10-11 November 2009. Bottom: corresponding HIPPO CO measurements (ppb).

Figure 9 depicts the HIPPO 2S campaign in more detail, showing the exact flight patterns and the differences with respect to MACC (MACC-HIPPO) at each measurement point (upper panel). For the sake of simplicity, we only show MACC here. The measured CO concentrations are shown in 
the lower panel. There is enhanced carbon monoxide (CO) at higher altitudes, indicating long-range transport of biomass burning at the time of overflight, which can explain the apparent model-HIPPO mismatch. The features span several degrees of latitude, excluding coarse model resolution as a reason for missing the plume. Thus, we hypothesize that the mismatch is caused by either underestimated $\mathrm{CO}$ emissions from the Global Fire Emissions Database (GFED, Randerson et al., 2013; which is used by both models) or transport errors in the models. For GOSAT, the mismatch is most likely caused by too lenient coincidence criteria, missing most of the biomass burning plume.

Overall, it can be concluded that GOSAT measurements can provide valuable and accurate information on the global $\mathrm{CO}_{2}$ distribution and meets the $0.5 \mathrm{ppm}$ bias criterion in most cases over the ocean. However, small sampling sizes precludes an in-depth analysis of potential large-scale biases in the data sets. In the future, OCO-2 with its much higher sampling density will help to disentangle measurement and modeling bias and guide inversion studies.

\section{Comparisons of mid- to upper-tropospheric $\mathrm{CO}_{2}$}

\subsection{TES $(\sim 510 \mathrm{hPa})$}

For the comparison with TES, we use the $510 \mathrm{hPa}$ retrieval layer and apply averaging kernel corrections using modelextended HIPPO data as truth, using both models independently and averaging results after averaging kernel correction. Coincidence criteria are identical to the GOSAT analysis but we require at least 20 valid TES soundings per HIPPO profile to reduce measurement noise. Similar to before, the TES error bars are empirically derived using the standard deviation of the co-located soundings.

Figure 10 shows the comparison of TES against HIPPO in the same way it was for GOSAT. The correlation $\left(r^{2}\right)$ is somewhat lower than for GOSAT but still very significant. Some differences exceed $2 \mathrm{ppm}$, albeit with a relatively high standard error, i.e., barely significant at the $2-\sigma$ level (see right panel, error bars indicate $1-\sigma$ ).

Given the larger standard error in TES data, differences may be purely noise driven and not necessarily a hint at largescale biases even though the clustering of positive anomalies, in particular in HIPPO 3 at higher latitudes, is apparent. As evident from Fig. 3, there are stronger vertical gradients at $15-45^{\circ} \mathrm{N}$ during HIPPO3 because they are close to the peak $\mathrm{CO}_{2}$ value caused by wintertime respiration. This can cause potential mismatches as gradients can be strong and co-location criteria might have to be more strict. In addition, the HIPPO profiles are extended by models to the top of atmosphere and are thus not entirely model independent.
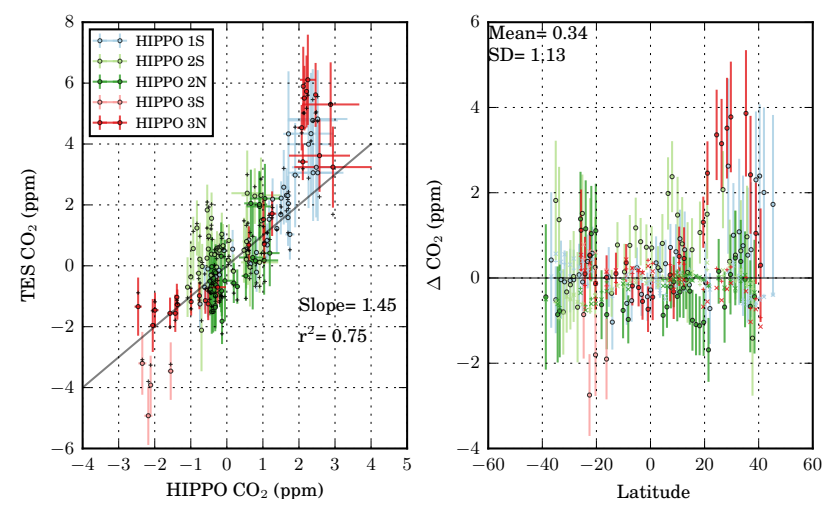

Figure 10. Left: scatter plot of normalized (with campaign average) $\mathrm{CO}_{2}$ from individual HIPPO profiles ( $x$ axis) against corresponding TES data. Right: difference plot of $\mathrm{CO}_{2}$ against latitude. Campaigns as well as north and southbound tracks are color coded, modelHIPPO differences are plotted as well. Please refer to Fig. 7 for a detailed legend.
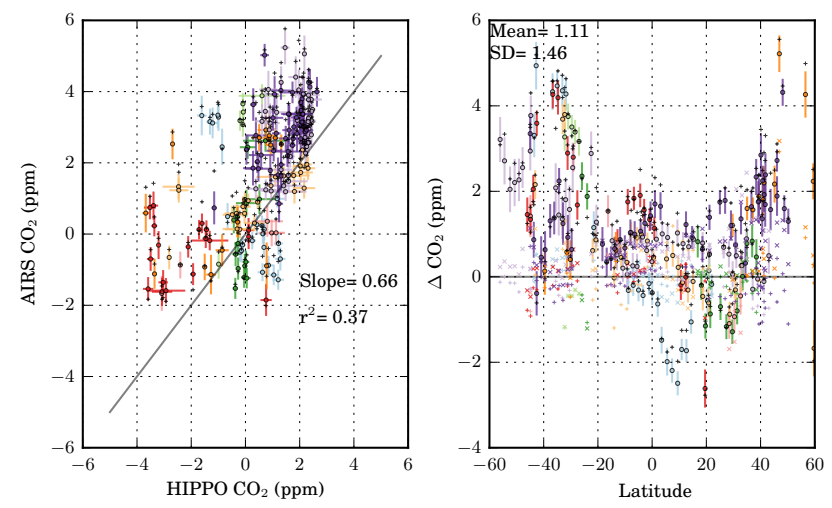

Figure 11. Left: scatter plot of normalized (with campaign average) $\mathrm{CO}_{2}$ from individual HIPPO profiles ( $x$ axis) against corresponding AIRS data. Right: difference plot of $\mathrm{CO}_{2}$ against latitude. Campaigns as well as north and southbound tracks are color coded, model-HIPPO differences are plotted as well. Please refer to Fig. 7 for a detailed legend.

\section{$5.2 \quad \operatorname{AIRS}(\sim 300 \mathrm{hPa})$}

For the comparison with AIRS (Fig. 11), the sensitivity maximum varies around $300 \mathrm{hPa}$ and we apply the averaging kernels similar to TES. Owing to the large data density and high single measurement noise of AIRS, we use a minimum of 50 co-locations for a comparison, still leaving many more data points than for the GOSAT and TES comparison. As coincidence criteria, we use data within $5^{\circ}$ latitude and longitude and $24 \mathrm{~h}$ time difference.

Even though the correlations are significant, a bias dependence on latitude can be observed, which hampers incorporation of AIRS data into flux inversions. The reason for these biases is currently unknown but may be related to changes in peak sensitivity altitude as a function of latitude. A full 
Table 1. Summary of all HIPPO comparisons. No. of profiles shows how many HIPPO profiles were used for the comparison. Correlation coefficients, fitted slope, mean difference $\mu$, and standard deviation $\sigma$ of the difference compared to HIPPO of all comparisons are computed using measurements normalized by the respective campaign average. For comparison, $\sigma$ of model-HIPPO for the satellite co-locations and respective sensitivity are provided as well.

\begin{tabular}{l|lllllll}
\hline & No. profiles & $r^{2}$ & slope & $\mu(\mathrm{ppm})$ & $\sigma(\mathrm{ppm})$ & $\sigma_{\mathrm{CT}}$ & $\sigma_{\text {MACC }}$ \\
\hline GOSAT & 94 & 0.85 & 0.99 & -0.06 & 0.45 & 0.42 & 0.36 \\
TES & 135 & 0.75 & 1.45 & 0.34 & 1.13 & 0.36 & 0.3 \\
AIRS & 200 & 0.37 & 0.66 & 1.11 & 1.46 & 0.63 & 0.47 \\
CT2013B & 676 & 0.93 & 0.95 & 0.10 & 0.51 & N/A & N/A \\
MACC & 674 & 0.95 & 1.00 & 0.06 & 0.43 & N/A & N/A \\
\hline
\end{tabular}

characterization of averaging kernels per sounding would alleviate these concerns. Given the observed larger model$\mathrm{HIPPO} \mathrm{CO}_{2}$ differences at higher altitudes, a fully characterized AIRS $\mathrm{CO}_{2}$ product could be worthwhile for the flux community. However, requirements for systematic biases in partial columns are even stricter than for the total column (Chevallier, 2015).

\section{Conclusions}

In this study, we compared atmospheric models as well as satellite data of $\mathrm{CO}_{2}$ against HIPPO profiles. Table 1 provides a high-level overview of the derived statistics. Both atmospheric models compare very similarly, both showing a very high correlation with respect to HIPPO, even when subtracting the campaign average $\mathrm{XCO}_{2}$, as is done throughout all comparisons. The largest discrepancies are found near $300 \mathrm{hPa}$ at higher latitudes during peak wintertime $\mathrm{CO}_{2}$ accumulation as well as the summer uptake period. These may be related to steep vertical gradients poorly resolved by the models. In addition, a biomass burning event in the Southern Hemisphere seems to have been underestimated by the models, causing discrepancies of around $1 \mathrm{ppm}$.

For GOSAT comparisons, results are comparable to those with models but the sample size is much smaller. OCO-2 could largely improve on GOSAT's data density over the oceans but did not overlap with the HIPPO measurement campaign period. The new Atmospheric Tomography Mission (ATom), selected as one of NASA's Earth Venture airborne missions, will potentially allow for similar comparisons to OCO-2 in the future and should provide enough data to draw more robust conclusions than using GOSAT.

In general, GOSAT compares very well to HIPPO, followed by TES and AIRS. For TES, most deviations can be explained by pure measurement noise but AIRS appears to exhibit some latitudinal biases that would need to be accounted for if used for source-inversion studies. On the other hand, systematic model transport errors that can affect source inversions (Deng et al., 2015) were confirmed here for both atmospheric models used. Despite initial skepticism towards using remotely sensed $\mathrm{CO}_{2}$ data for global carbon-cycle in- version, we are now reaching a state where potential systematic errors in both remote sensing as well as atmospheric modeling can play an equally crucial part. Innovative methods to characterize and ideally minimize both of these error sources will be needed in the future. One option is to apply flux inversion schemes that co-retrieve systematic biases alongside fluxes, such as in Bergamaschi et al. (2007), using prior knowledge on potential physical insight into systematic biases, such as aerosol interference, land/ocean biases or air mass factors.

\section{Data availability}

CarbonTracker CT2013B data are available at http:// carbontracker.noaa.gov. MACC data are available at https: //atmosphere.copernicus.eu. TES data are available at http: //tes.jpl.nasa.gov/data/. HIPPO data are available at http: //hippo.ornl.gov. AIRS data are available at http://disc.sci. gsfc.nasa.gov/uui/datasets?keywords=AIRS. GOSAT data processed by NASA/JPL as well as a general $\mathrm{CO}_{2}$ repository are available at http://co2.jpl.nasa.gov.

Acknowledgements. Funded by NASA Roses ESDR-ERR 10/10ESDRERR10-0031, "Estimation of biases and errors of $\mathrm{CO}_{2}$ satellite observations from AIRS, GOSAT, SCIAMACHY, TES, and OCO-2". We thank the entire HIPPO team for making these measurements possible and the NIES and JAXA GOSAT teams for designing and operating the GOSAT mission and generously sharing L1 data with the ACOS project. Andy Jacobson (NOAA ESRL, Boulder, Colorado) provided CarbonTracker CT2013B results and advised in data usage and interpretation.

Edited by: M. Chipperfield 


\section{References}

Basu, S., Krol, M., Butz, A., Clerbaux, C., Sawa, Y., Machida, T., Matsueda, H., Frankenberg, C., Hasekamp, O., and Aben, I.: The seasonal variation of the $\mathrm{CO}_{2}$ flux over Tropical Asia estimated from GOSAT, CONTRAIL, and IASI, Geophys. Res. Lett., 41, 1809-1815, 2014.

Bergamaschi, P., Frankenberg, C., Meirink, J. F., Krol, M., Dentener, F., Wagner, T., Platt, U., Kaplan, J. O., Körner, S., Heimann, M., Dlugokencky, E. J., and Goede, A.: Satellite chartography of atmospheric methane from SCIAMACHY on board ENVISAT: 2. Evaluation based on inverse model simulations, J. Geophys. Res.-Atmos., 112, D02304, doi:10.1029/2006JD007268, 2007.

Chahine, M., Barnet, C., Olsen, E. T., Chen, L., and Maddy, E.: On the determination of atmospheric minor gases by the method of vanishing partial derivatives with application to $\mathrm{CO}_{2}$, Geophys. Res. Lett., 32, L22803, doi:10.1029/2005GL024165, 2005.

Chevallier, F.: On the statistical optimality of $\mathrm{CO}_{2}$ atmospheric inversions assimilating $\mathrm{CO}_{2}$ column retrievals, Atmos. Chem. Phys., 15, 11133-11145, doi:10.5194/acp-15-11133-2015, 2015.

Deng, F., Jones, D. B. A., Walker, T. W., Keller, M., Bowman, K. W., Henze, D. K., Nassar, R., Kort, E. A., Wofsy, S. C., Walker, K. A., Bourassa, A. E., and Degenstein, D. A.: Sensitivity analysis of the potential impact of discrepancies in stratospheretroposphere exchange on inferred sources and sinks of $\mathrm{CO}_{2}$, Atmos. Chem. Phys., 15, 11773-11788, doi:10.5194/acp-1511773-2015, 2015.

GHG-CCI: User Requirements Document for the GHG-CCI project of ESA's Climate Change Initiative, 38 pp., version 2, 28 Aug. 2014, Tech. rep., ESA, available at: http://www.esa-ghg-cci.org/ $? q=$ webfm_send/173, 2014

Guerlet, S., Basu, S., Butz, A., Krol, M., Hahne, P., Houweling, S., Hasekamp, O., and Aben, I.: Reduced carbon uptake during the 2010 Northern Hemisphere summer from GOSAT, Geophys. Res. Lett., 40, 2378-2383, 2013.

Hamazaki, T., Kaneko, Y., Kuze, A., and Kondo, K.: Fourier transform spectrometer for greenhouse gases observing satellite (GOSAT), in: Proceedings of SPIE, vol. 5659, p. 73, 2005.

Hourdin, F. and Armengaud, A.: The use of finite-volume methods for atmospheric advection of trace species - Part I: Test of various formulations in a general circulation model, Mon. Weather Rev., 127, 822-837, 1999.

Hourdin, F., Musat, I., Bony, S., Braconnot, P., Codron, F., Dufresne, J.-L., Fairhead, L., Filiberti, M.-A., Friedlingstein, P., Grandpeix, J.-Y., Krinner, G., LeVan, P., Li, Z.-X., and Lott, F.: The LMDZ4 general circulation model: climate performance and sensitivity to parametrized physics with emphasis on tropical convection, Clim. Dynam., 27, 787-813, doi:10.1007/s00382006-0158-0, 2006.

Houweling, S., Baker, D., Basu, S., Boesch, H., Butz, A., Chevallier, F., Deng, F., Dlugokencky, E. J., Feng, L., Ganshin, A., Hasekamp, O., Jones, D., Maksyutov, S., Marshall, J., Oda, T., O’Dell, C. W., Oshchepkov, S., Palmer, P. I., Peylin, P., Poussi, Z., Reum, F., Takagi, H., Yoshida, Y., and Zhuravlev, R.: An intercomparison of inverse models for estimating sources and sinks of $\mathrm{CO}_{2}$ using GOSAT measurements, J. Geophys. Res.-Atmos., 120, 5253-5266, doi:10.1002/2014JD022962, 2015.
Keppel-Aleks, G., Wennberg, P. O., and Schneider, T.: Sources of variations in total column carbon dioxide, Atmos. Chem. Phys., 11, 3581-3593, doi:10.5194/acp-11-3581-2011, 2011.

Keppel-Aleks, G., Wennberg, P. O., Washenfelder, R. A., Wunch, D., Schneider, T., Toon, G. C., Andres, R. J., Blavier, J.-F., Connor, B., Davis, K. J., Desai, A. R., Messerschmidt, J., Notholt, J., Roehl, C. M., Sherlock, V., Stephens, B. B., Vay, S. A., and Wofsy, S. C.: The imprint of surface fluxes and transport on variations in total column carbon dioxide, Biogeosciences, 9, 875891, doi:10.5194/bg-9-875-2012, 2012.

Krol, M., Houweling, S., Bregman, B., van den Broek, M., Segers, A., van Velthoven, P., Peters, W., Dentener, F., and Bergamaschi, P.: The two-way nested global chemistry-transport zoom model TM5: algorithm and applications, Atmos. Chem. Phys., 5, 417432, doi:10.5194/acp-5-417-2005, 2005.

Kulawik, S. S., Worden, J. R., Wofsy, S. C., Biraud, S. C., Nassar, R., Jones, D. B. A., Olsen, E. T., Jimenez, R., Park, S., Santoni, G. W., Daube, B. C., Pittman, J. V., Stephens, B. B., Kort, E. A., Osterman, G. B., and TES team: Comparison of improved Aura Tropospheric Emission Spectrometer $\mathrm{CO}_{2}$ with HIPPO and SGP aircraft profile measurements, Atmos. Chem. Phys., 13, 32053225, doi:10.5194/acp-13-3205-2013, 2013.

Kulawik, S., Wunch, D., O’Dell, C., Frankenberg, C., Reuter, M., Oda, T., Chevallier, F., Sherlock, V., Buchwitz, M., Osterman, G., Miller, C. E., Wennberg, P. O., Griffith, D., Morino, I., Dubey, M. K., Deutscher, N. M., Notholt, J., Hase, F., Warneke, T., Sussmann, R., Robinson, J., Strong, K., Schneider, M., De Mazière, M., Shiomi, K., Feist, D. G., Iraci, L. T., and Wolf, J.: Consistent evaluation of ACOS-GOSAT, BESD-SCIAMACHY, CarbonTracker, and MACC through comparisons to TCCON, Atmos. Meas. Tech., 9, 683-709, doi:10.5194/amt-9-683-2016, 2016.

Kuze, A., Suto, H., Nakajima, M., and Hamazaki, T.: Thermal and near infrared sensor for carbon observation Fourier-transform spectrometer on the Greenhouse Gases Observing Satellite for greenhouse gases monitoring, Appl. Opt., 48, 6716-6733, 2009.

Lindqvist, H., O’Dell, C. W., Basu, S., Boesch, H., Chevallier, F., Deutscher, N., Feng, L., Fisher, B., Hase, F., Inoue, M., Kivi, R. Morino, I., Palmer, P. I., Parker, R., Schneider, M., Sussmann, R., and Yoshida, Y.: Does GOSAT capture the true seasonal cycle of carbon dioxide?, Atmos. Chem. Phys., 15, 13023-13040, doi:10.5194/acp-15-13023-2015, 2015.

Miller, C. E., Crisp, D., DeCola, P. L., Olsen, S. C., Randerson, J. T., Michalak, A. M., Alkhaled, A., Rayner, P., Jacob, D. J., Suntharalingam, P., Jones, D. B. A., Denning, A. S., Nicholls, M. E., Doney, S. C., Pawson, S., Boesch, H., Connor, B. J., Fung, I. Y., O'Brien, D., Salawitch, R. J., Sander, S. P., Sen, B., Tans, P., Toon, G. C., Wennberg, P. O., Wofsy, S. C., Yung, Y. L., and Law, R. M.: Precision requirements for space-based data, J. Geophys. Res.-Atmos., 112, D10314, doi:10.1029/2006JD007659, , 2007.

O’Dell, C. W., Connor, B., Bösch, H., O’Brien, D., Frankenberg, C., Castano, R., Christi, M., Eldering, D., Fisher, B., Gunson, M., McDuffie, J., Miller, C. E., Natraj, V., Oyafuso, F., Polonsky, I., Smyth, M., Taylor, T., Toon, G. C., Wennberg, P. O., and Wunch, D.: The ACOS $\mathrm{CO}_{2}$ retrieval algorithm - Part 1: Description and validation against synthetic observations, Atmos. Meas. Tech., 5, 99-121, doi:10.5194/amt-5-99-2012, 2012.

Olsen, E. T. and Licata, S. J.: AIRS Version 5 Release Tropospheric $\mathrm{CO}_{2}$ Products, Tech. rep., Jet Propulsion Laboratory, California 
Institute of Technology, available at: http://disc.sci.gsfc.nasa. gov/AIRS/documentation/v5_docs/AIRS\%_V5_Release_User_ Docs/AIRS-V5-Tropospheric-CO2-Products.pdf, 2014.

Peters, W., Jacobson, A. R., Sweeney, C., Andrews, A. E., Conway, T. J., Masarie, K., Miller, J. B., Bruhwiler, L. M. P., brielle Petron, G., Hirsch, A. I., Worthy, D. E. J., van der Werf, G. R., Randerson, J. T., Wennberg, P. O., Krol, M. C., and Tans, P. P.: An atmospheric perspective on North American carbon dioxide exchange: CarbonTracker, P. Natl. Acad. Sci. USA, 104, 18925 18 930, doi:10.1073/pnas.0708986104, 2007.

Randerson, J., van der Werf, G., Giglio, L., Collatz, G., and Kasibhatla, P.: Global Fire Emissions Database, Version 3 (GFEDv3.1), Tech. rep., ORNL, doi:10.3334/ORNLDAAC/1191, 2013.

Reuter, M., Bovensmann, H., Buchwitz, M., Burrows, J., Connor, B., Deutscher, N. M., Griffith, D., Heymann, J., KeppelAleks, G., Messerschmidt, J., Notholt, J., Petri, C., Robinson, J., Schneising, O., Sherlock, V., Velazco, V., Warneke, T., Wennberg, P. O., and Wunch, D.: Retrieval of atmospheric $\mathrm{CO}_{2}$ with enhanced accuracy and precision from SCIAMACHY: Validation with FTS measurements and comparison with model results, J. Geophys. Res-Atmos., 116, D04301, doi:10.1029/2010JD015047, 2011.

Schneising, O., Reuter, M., Buchwitz, M., Heymann, J., Bovensmann, H., and Burrows, J. P.: Terrestrial carbon sink observed from space: variation of growth rates and seasonal cycle amplitudes in response to interannual surface temperature variability, Atmos. Chem. Phys., 14, 133-141, doi:10.5194/acp-14-1332014, 2014.
Stephens, B. B., Gurney, K. R., Tans, P. P., Sweeney, C., Peters, W., Bruhwiler, L., Ciais, P., Ramonet, M., Bousquet, P., Nakazawa, T., Aoki, S., Machida, T., Inoue, G., Vinnichenko, N., Lloyd, J., Jordan, A., Heimann, M., Shibistova, O., Langenfelds, R. L., Steele, L. P., Francey, R. J., and Denning, A. S.: Weak northern and strong tropical land carbon uptake from vertical profiles of atmospheric $\mathrm{CO}_{2}$, Science, 316, 1732-1735, 2007.

Wofsy, S. C.: HIAPER Pole-to-Pole Observations (HIPPO): finegrained, global-scale measurements of climatically important atmospheric gases and aerosols, Philos. T. R. Soc. A, 369, 20732086, doi:10.1098/rsta.2010.0313, 2011.

Wunch, D., Wennberg, P. O., Toon, G. C., Connor, B. J., Fisher, B., Osterman, G. B., Frankenberg, C., Mandrake, L., O’Dell, C., Ahonen, P., Biraud, S. C., Castano, R., Cressie, N., Crisp, D., Deutscher, N. M., Eldering, A., Fisher, M. L., Griffith, D. W. T., Gunson, M., Heikkinen, P., Keppel-Aleks, G., Kyrö, E., Lindenmaier, R., Macatangay, R., Mendonca, J., Messerschmidt, J., Miller, C. E., Morino, I., Notholt, J., Oyafuso, F. A., Rettinger, M., Robinson, J., Roehl, C. M., Salawitch, R. J., Sherlock, V., Strong, K., Sussmann, R., Tanaka, T., Thompson, D. R., Uchino, O., Warneke, T., and Wofsy, S. C.: A method for evaluating bias in global measurements of $\mathrm{CO}_{2}$ total columns from space, Atmos. Chem. Phys., 11, 12317-12337, doi:10.5194/acp11-12317-2011, 2011. 